
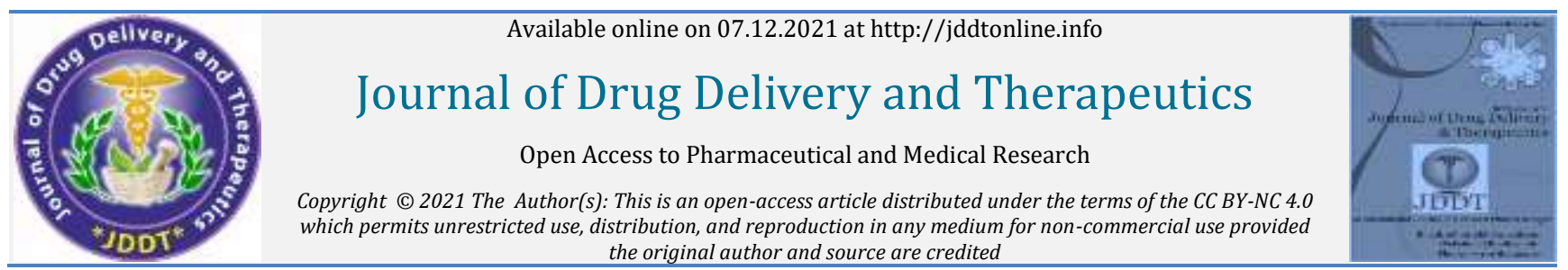

\title{
Formulation and evaluation of taste masked oral disintegrating tablets of lornoxicam
}

\author{
Kritika Rai, Vivek Jain, Sunil Kumar Jain, Pushpendra Kumar Khangar*
}

Adina Institute of Pharmaceutical Science, NH86A, Lahdara, Sagar, MP 470001

\section{Article Info:

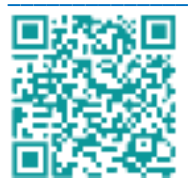 \\ Article History: \\ Received 13 October 2021 \\ Reviewed 23 November 2021 \\ Accepted 29 November 2021 \\ Published 07 December 2021}

\section{Cite this article as:}

Rai K, Jain V, Jain SK, Khangar PK, Formulation and evaluation of taste masked oral disintegrating tablets of lornoxicam, Journal of Drug Delivery and

Therapeutics. 2021; 11(5):115-120

DOI: http://dx.doi.org/10.22270/jddt.v11i5.5124

\begin{abstract}
Orally disintegrating tablets (ODT) disintegrate quickly with saliva when administered into the oral cavity and taken without water or chewed. ODT are easy to take for children and the elderly, who may experience difficultly in taking ordinary oral preparations such as tablets, capsules, and powders. The ODT threes substantial benefits for the patient (or elder) who cannot swallow (Dysphagia), or who is not permitted water intake due to disease. The reason of the current research was to prepare taste masking oral disintegrating tablets of poorly soluble lornoxicam (LXM) by direct compression technique using Kyron T-114 (cation exchange resin) as a taste masking agent. With in various ratios the Drug-resin of 1:4 was established to present best taste masking. The superdisintegrants used in formulation are croscarmellose sodium and cross povidone. Among these croscarmellose sodium demonstrated superior drug release. The tablets were evaluated for friability, weight variation, wetting time, hardness, disintegration time and uniformity of content. Optimized formulations were evaluated for in vitro dissolution test. Amongst all the formulations F- 6 was found to be most successful tablets prepared by this technique had disintegration time of $30 \mathrm{sec}$ and \% CDR 94.78 within 30min. Hence, this advance can be utilized for taste masking of bitter pharmaceutical ingredients leading to superior patient compliance.
\end{abstract}

Keywords: Oral disintegration tablets, Lornoxicam, Kyron T-114, Superdisintegrants, Direct Compression.

\footnotetext{
*Address for Correspondence: Pushpendra Kumar Khangar, Adina Institute of Pharmaceutical Science, NH86A, Lahdara, Sagar, MP 470001
}

\section{INTRODUCTION}

Pharmaceutical science and technology has advancement extremely in the current years. This increased consciousness and has consequences in an increased sophistication and level of proficiency in the design, development, manufacture, testing and regulation of drugs and dosage forms ${ }^{1}$. Today, immense significance is given to the organoleptic characteristics of pharmaceutical products mostly appearance, odour and taste. Customer approval for pharmaceutical products is mostly dependent on visual appearance, taste and textural properties ${ }^{2}$. Any drug has helpful result when it is accepted and taken correctly by the patient where flavor, fragrance and colour in a pharmaceutical product add to its approval. Taste, smell, texture and aftertaste are significant features in the expansion of oral dosage forms and organization of parameters for leading paediatric patient compliance 3 . Unwanted taste is one of numerous considerable formulation difficulties that are meted with certain drugs, and masking of the unlikable taste of a drug develops the product value ${ }^{3}$. With reverence to patient adequacy and fulfillment, taste is one of the major issues influential the market penetration and commercial achievement of oral formulations, particularly in pediatric medicine ${ }^{4}$. Hence, pharmaceutical industries spend time, money and resources into developing edible and agreeable tasting products because good tasting products not only improve the patient compliance but also give a competitive advantage. When a therapeutic category is crowded with similar products (e.g. anti-infective) and provides brand recognition to combat private-label competition as consumers will choose the brand that has the least objectionable taste. Thus, in the current days, taste masking of bitter agents in the pharmaceutical industry has become commercially inspired activity for enormous success of the product ${ }^{5}$. A lot of technologies were urbanized for the manufacturing of robust and adaptable tablets with taste-masking and controlling release pattern. One such approach is the orally disintegrating tablets. ODT's offers a immense benefit for patients having complexity in swallowing (dysphasia) ${ }^{6}$. In latest days ODTs technology that creates tablets dissolve or disintegrate in the oral cavity without the intake of any extra water drawn a immense deal of attention? ${ }^{7}$. In current days ODTs for a variety of categories of drugs were urbanized 8 . Formulating ODTs of poorly water-soluble drugs also progress its oral bioavailability. But in ODTs, for palatability and patient fulfillment taste of the drugs participates a significant role. Numerous dissimilar oral pharmaceuticals and bulking agents have unpleasant or bitter-tasting components. So many dissimilar formulations are developed 
with a desire to progress the palatability of the drug by improving feat and appropriateness. Assorted techniques have been developed to progress taste like polymeric coatings strategies, ion exchange resins, salt formation, complexation with cyclodextrins, using liposomes, microencapsulation techniques and coating or granulation ${ }^{9}$. Kyron T-114(cation exchange resin) is frequently employed as a taste masking agent resulting from croslinked polymer of methacrylic acid. Strong bitter taste of LXM was masked with drug resin ratio of 1:2; this advance can be employed for taste masking of bitter pharmaceutical ingredients and can make entitled to formulate mouth disintegrating dosage form ${ }^{10}$. The model drug, LXM is a NSAID belonging to the oxicam class. It is one of the strongest analgesics and antiinflammatory agents along with all types of NSAIDs. It inhibits the action of prostaglandin and thromboxane synthesis by inhibition of cyclooxygenase (both COX-1 and COX-2). LXM has a short half-life contrasted to the other oxicams, and for this cause, LXM is incorporated in treatment protocols of postoperative pain and RA ${ }^{11}$. LXM is poorly soluble in water and has a bitter taste .It is absorbed quickly and almost entirely from the GIT. Consequently to give this drug in a easier to get to and patient compliant form, in the current study an effort has been made to mask its bitter taste and formulate in to oral disintegrating tablet.

\section{MATERIALS AND METHODS}

\section{Materials}

LXM was obtained as a gift sample from Hetero drugs Ltd. (Hyderabad, India). Polyacrylic acid (kyron T-114), cross carmellose sodium and lactose monohydrate were purchased from S.D Fine Chemical Limited, Mumbai. Cross povidone, sucralose, colloidal silicon dioxide, magnesium stearates were purchased from Qualigens Fine chemicals, New Delhi. Double distilled water was prepared freshly and used whenever required. All other chemicals used in this study including those stated were of analytical reagent (A.R.) grade.

\section{Preformulation studies}

\section{Physical characteristics}

By visual examination, the drug was recognized for physical characters like colour, texture, odour etc.

\section{Solubility}

Solubility of the drug was indomitable by taking some amount of drug (about 1-2 mg) in the test tube individually and added the $5 \mathrm{ml}$ of the solvent (water, ethanol, methanol, $0.1 \mathrm{~N} \mathrm{HCL}, 0.1 \mathrm{~N} \mathrm{NaOH}$, chloroform and $7.4 \mathrm{pH}$ buffer) shake vigorously and kept for some time. Note the solubility of the drug in various solvents (at room temperature).

\section{Melting point determination}

Melting point of drug was indomitable by Open capillary method.

\section{Determination of $\lambda_{\text {max }}$ of $L X M$}

Exactly weighed $100 \mathrm{mg}$ of drug was dissolved in $30 \mathrm{ml}$ of $0.1 \mathrm{~N} \mathrm{NaOH}$, then volume was adjusted to $100 \mathrm{ml}$ with $\mathrm{pH} 7.4$ phosphate buffer (stock solution $1000 \mu \mathrm{g} / \mathrm{ml}$ ). From this 10 $\mathrm{ml}$ of solution was taken and the volume was adjusted to 100 $\mathrm{ml}$ with pH 7.4 phosphate buffer $(100 \mu \mathrm{g} / \mathrm{ml})$. The above solution was subsequently diluted with $\mathrm{pH} 7.4$ buffers to obtain the series of dilutions containing $2,4,6,8$, and $10 \mu \mathrm{g} / \mathrm{ml}$. The absorbance of the above dilutions was measured at $376 \mathrm{~nm}$ by using a UV-Spectrophotometer
(Shimadzu-1800), taking pH 7.4 phosphate buffer as the blank.

\section{FTIR spectroscopy}

Identification of LXM was done by FTIR spectroscopy with respect to marker compound. It was identified from the result of IR spectrum as per specification. FTIR spectra recorded on $\mathrm{KBr}$ disk method using Brukers Alpha spectrophotometer with IR solution software. Sample powder was carefully mixed by triturating with $\mathrm{KBr}$ in a glass mortar with pestle and compressed into disks in a hydraulic press (Techno search Instruments, India). FTIR spectra of all the samples were recorded over a spectral region from 4700 to $400 \mathrm{~cm}-1$ using 20 scans with $4 \mathrm{~cm}-1$ resolution.

\section{Drug-excipients compatibility study}

Excipients are usually a pharmacologically inactive substance used as a carrier for the active ingredients of a medication. Drug and excipients were mixed individually in proportion (1:1) i.e (1:1 gm) for performing compatibility studies. The glass vials were sealed and placed in the stability chamber at $25^{\circ} \mathrm{C} / 60 \% \mathrm{RH}$ (Open \& Close), $40^{\circ} \mathrm{C} / 75$ $\%$ RH (Open \& Close) and $60^{\circ} \mathrm{C}$ for 21 days. The sample was withdrawn and analyzed for colour change, and odours after 7,15 , and 21 days. The IR spectra was taken after 10 days and 15 days and analyzed for any shift in major peaks. The primary objective of this investigation was to identify any incompatibility existing between ingredients.

\section{Optimization}

\section{Ratio of LXM and ion exchange resin}

Weighed amount of LXM was dispersed in water and stirred for 10 to 15 minutes. To the above dispersion Kyron T-114 was added and stirred on magnetic stirrer until the taste masking was observed showing in table 1. LXM and Kyron T114 was taken in 1:4 ratio and stirred at suitable RPM as per the below table 2 .

\section{Table1 Optimization ratio of LXM and ion exchange} resin

\begin{tabular}{|c|c|}
\hline $\begin{array}{c}\text { Ratio of LXM and } \\
\text { Kyron T-114 }\end{array}$ & Observation \\
\hline $1: 1$ & Complex was bitter in taste \\
\hline $1: 2$ & Complex was bitter in taste \\
\hline $1: 3$ & $\begin{array}{c}\text { Complex was slightly bitter in } \\
\text { taste }\end{array}$ \\
\hline $1: 4$ & Taste masking was observed \\
\hline
\end{tabular}

Table 2 Optimization stirring time of drug and ion exchange resin

\begin{tabular}{|c|c|}
\hline Time in (Hrs.) & Observation \\
\hline 0.5 & Taste masking was not observed \\
\hline $1: 0$ & Taste masking was not observed \\
\hline 2.0 & Slightly bitter taste \\
\hline 3.0 & Complete taste masking observed \\
\hline
\end{tabular}




\section{Preparation of drug-resinate granules \& lubrication}

After drug-resin mixtures were stirred for necessary time, the drug-resinates were scrupulously washed with demineralized water for numerous times then filtered by using Whatman's filter paper and dried. The powdered drugresinate particles are wetted, made into damp mass. Then passed through sieve no- 16 and dried at $60^{\circ} \mathrm{C}$ for 30 minutes. The dried granules are again passed through sieve no-16 over sieve no-44 to get uniform granules. These dried granules were lubricated with the appropriate excipients and used for the compression of the LXM Orally disintegrating tablets. Numerous trails were made to finalize the suitable disintegrant as shown in the Table 3 . After finalization of the appropriate concentration of the Polyacrylic acid (Kyron T-114) and the suitable disintegrating agent, numerous trails were taken with sweeteners and finally flavor to further improve the acceptance of the LXM ODT dosage form.

Table 3 Formulation development of different trial batches

\begin{tabular}{|c|c|c|c|c|c|c|c|}
\hline S. no & Ingredient & F1 & F2 & F3 & F4 & F5 & F6 \\
\hline \multicolumn{8}{|c|}{ Complexation } \\
\hline 1 & LXM & 8 & 8 & 8 & 8 & 8 & 8 \\
\hline 2 & Kyron T-114 & 8 & 12 & 16 & 24 & 32 & 32 \\
\hline 3 & Purified water & q.s. & q.s. & q.s. & q.s. & q.s. & q.s. \\
\hline \multicolumn{8}{|c|}{ Dry mixing } \\
\hline 4 & Lactose monohydrate & 14 & 14 & 14 & 14 & 14 & 14 \\
\hline 5 & Vannila flavour & 5 & - & 8 & 3 & 10 & 10 \\
\hline 6 & Aspartame & 5 & - & 8 & 8 & 10 & 10 \\
\hline 7 & CCS & 2 & 5 & - & 3 & 7 & 7 \\
\hline 8 & Crospovidone XL & 3 & - & 5 & 7 & - & - \\
\hline 9 & Mango flavour & 4 & 3 & 2 & 10 & 7 & 7 \\
\hline 10 & Mannitol SD 200 & 200 & 206.6 & 187 & 170.8 & 158 & 158 \\
\hline \multicolumn{8}{|c|}{ Pre-lubrication } \\
\hline 11 & Colloidal silicon dioxide & 0.6 & 0.6 & 1.2 & 1.2 & 2.0 & 2.0 \\
\hline \multicolumn{8}{|c|}{ Lubrication } \\
\hline \multirow[t]{2}{*}{12} & Magnesium stearate & 0.4 & 0.8 & 0.8 & 1.0 & 2.0 & 2.0 \\
\hline & Total Weight (in mg) & 250 & 250 & 250 & 250 & 250 & 250 \\
\hline
\end{tabular}

\section{Evaluation of LXM-ODT tablets}

\section{Pre-compression parameters}

\section{Angle of repose}

The angle of repose of blends was indomitable by the funnel method. The exactly weighed blend was taken in the funnel. The height of the funnel was attuned in such a way that the tip of the funnel just touched the apex of the heap of the blend. The blend was permitted to flow from the funnel on the surface. The diameter and height of the heap formed from the blend were measured. The angle of repose was calculated using the following formula 12 .

$$
\operatorname{Tan} \theta=h / r
$$

Where, " $h$ " is the height of the heap and " $r$ " is the radius of the heap of granules.

\section{Bulk density (BD)}

An exactly weighed powder blend from every formula was lightly shaken to break any agglomerates formed and it was established in to a measuring cylinder. The volume occupied by the powder was calculated which gave bulk volume. The LXM of powder blends was determined using the following formula ${ }^{13}$.
Bulk density $=$ Total weight of powder $/$ Total volume of powder

\section{Tapped bulk density (TBD)}

An exactly weighed powder blend from every formula was lightly shaken to break any agglomerates formed and it was introduced into a measuring cylinder. The measuring cylinder was tapped until no further change in volume was noted which gave the tapped volume. The TBD of powder blends was determined using the following formula ${ }^{14}$.

TBD $=$ Total weight of powder/Total volume of tapped powder

\section{Carr's compressibility index}

The Carr's compressibility index was considered from bulk density (BD) and tapped density of the blend. A quantity of 2 gm of blend from each formulation, filled into a $10 \mathrm{ml}$ of measuring cylinder. Initial bulk volume was measured, and cylinder was allowed to tap from the height of $2.5 \mathrm{~cm}$. The tapped frequency was $25 \pm 2 /$ min to measure the tapped volume of the blend. The $\mathrm{BD}$ and tapped density were calculated by using the bulk volume and tapped volume. Carr's compressibility index was calculated using the following formula15, 16 . 
Carr's compressibility index $(\%)=[($ Tapped density-Bulk density) $\times 100] /$ Tapped density

\section{Hausner's Ratio}

It is the measurement of frictional resistance of the drug. The ideal range should be 1.2-1.5, it was determined by the ratio of tapped density and bulk density.

$$
\text { HR = Tapped Density/ Bulk Density }
$$

\section{Post-compression parameters}

\section{Shape of tablet}

Directly compressed tablets were inspected under the magnified lens for the shape.

\section{Thickness}

20 tablets from the envoy sample were randomly taken and individual tablet thickness was measured by using digital vernier caliper ${ }^{17}$.

\section{Hardness}

Tablet hardness was deliberate by using Monsanto hardness tester. From every batch 6 tablets were measured for the hardness and average of 6 values was noted along with standard deviations ${ }^{18}$

\section{Friability test}

From every batch, 10 tablets were exactly weighed and placed in the friability test apparatus (Roche friabilator). Apparatus was operated at $25 \mathrm{rpm}$ for 4 minutes and tablets were observed while rotating. The tablets were then taken after 100 rotations, de dusted and reweighed. The friability was calculated as the percentage weight loss. \% friability was calculated as follows

$$
\% \text { Friability }=(\mathrm{W} 1-\mathrm{W} 2) \times 100 / \mathrm{W} 1
$$

Where $\mathrm{W} 1$ = Initial weight of the 10 tablets, $\mathrm{W} 2=$ Final weight of the 10 tablets after testing.

Friability values below $0.5-1 \%$ are generally acceptable ${ }^{18}$.

\section{Weight variation test}

To study weight variation individual weights (WI) of 20 tablets from every formulation were noted using electronic balance. Their average weight (WA) was calculated. \% weight variation was calculated as follows. Average weights of the tablets along with standard deviation values were calculated.

\section{Drug content}

The test is compulsory for tablets with $10 \mathrm{mg}$ or less weight of active ingredient. 10 randomly selected tablets from each formulation (F1 to F6) were finely powdered and drug equivalent to $10 \mathrm{mg}$ of drug dissolved in $10 \mathrm{ml}$ phosphate buffer $\mathrm{pH} 7.4$ sonicate it for 20 minutes, till the entire drug leached out from complex, then the solution was filtered through whatman filter paper No. 41. From this solution take $1 \mathrm{ml}$ and diluted up to $100 \mathrm{ml}$ with phosphate buffer $\mathrm{pH}$ 7.4 and the drug content was indomitable spectrophotometrically at $376 \mathrm{~nm}$.

\section{Disintegration time}

The USP device to test disintegration was 6 glass tubes that are 3 long open at the top, and held against 10screen at the bottom end of the basket rack assembly. One tablet is placed in each tube and the basket rack is positioned in 1 liter beaker of distilled water at $37 \pm 2{ }^{\circ} \mathrm{C}$, such that the tablets remain below the surface of the liquid on their upward movement and descend not closer than $2.5 \mathrm{~cm}$ from the bottom of the beaker.

\section{In vitro dissolution studies}

In vitro dissolution of LXM fast dissolving tablets was studied in USP XXIII type-II dissolution apparatus (Lab India ds2800) employing a paddle stirrer at $50 \mathrm{rpm}$ using $900 \mathrm{ml}$ of $\mathrm{pH} 7.4$ phosphate buffer at $37 \pm 0.5^{\circ} \mathrm{C}$ as dissolution medium. One tablet was used in each test. Aliquots of dissolution medium $(5 \mathrm{ml})$ were withdrawn at specified intervals of time $(5,10,15,20,30 \mathrm{~min}$ respectively) and analyzed for drug content by measuring the absorbance at $376 \mathrm{~nm}$. The volume withdrawn at each time interval was replaced with fresh quantity of dissolution medium. Cumulative percent LXM released was calculated and plotted against time.

\section{RESULTS AND DISCUSSION}

LXM was establish to be yellow crystalline powder in appearance, slightly unctuous with faint odour and had a bitter taste. The melting point of LXM (pure drug) was established to be $226-228^{\circ} \mathrm{C}$; it matches with the standard $\left(228^{\circ} \mathrm{C}\right)$. LXM was freely soluble in ethanol, DMSO, DMF, 0.1 $\mathrm{N} \mathrm{HCl}$, slightly soluble in $0.1 \mathrm{~N} \mathrm{NaOH}$, distilled water and soluble in chloroform, phosphate buffer pH 7.4. Identification of LXM was done by FTIR spectroscopy with admiration to marker compound. It was identified from the result of IR spectrum as per specification Fig.1. The calibration curve of LXM was found to be linear in the concentration range of $2-10 \mu \mathrm{g} / \mathrm{ml}$ at $376 \mathrm{~nm}$. Drugexcipients compatibility study exposed that physical mixture of drug and excipients were compatible upon contact to RT $\left(25^{\circ} \mathrm{C} \pm 2^{\circ} \mathrm{C} / 60 \% \pm 5 \%\right)$, accelerated condition $\left(40^{\circ} \mathrm{C} \pm 2{ }^{\circ} \mathrm{C} / 75 \% \pm 5 \% \mathrm{RH}\right)$ and at extreme condition $\left(60^{\circ} \mathrm{C}\right)$ at intervals of 1, 2 and 3 weeks. The sample was analyzed for colour change, and odours after 7, 15, and 21 days. There was no modify in the appearance of the physical mixture of drug \& various excipients used, nor in the odour coming out of the physical mixture. The IR spectra were taken after 10 days and 15 days and were analyzed. No shifting in major peaks was seen. By using these excipients prototype formulation was developed. From the results obtained for drug-excipients compatibility study, it was establish that the drug was compatible with the respective excipients under evaluation based on physical observation after 21 days. Tablet powder blend was subjected to a variety of precompression parameters Table 4 . The angle of repose values point to that the powder blend has good flow properties. The bulk density of all the formulations was establish to be in the range of 0.370 to $0.601\left(\mathrm{gm} / \mathrm{cm}^{3}\right)$ showing that the powder has good flow properties. The tapped density of all the formulations was establish to be in the range of 0.410 to 0.677 showing the powder has good flow properties. The compressibility index of all the formulations was found to be ranging between 10.17 to 14.16 which show that the powder has good flow properties. All the formulations have shown the Hauser's ratio ranging between 1.10 to 1.15 indicating the powder has good flow properties. The results of postcompression parameters such as the uniformity of weight, hardness, thickness, friability and disintegration time of the tablets are given in Table 5. All the tablets of different batches complied with the official requirements of uniformity of weight. The hardness of the tablets ranged from $9.1 \pm 0.11$ to $9.5 \pm 010 \mathrm{~kg} / \mathrm{cm}^{2}$ and the friability values were less than $0.5 \%$ signifying that the matrix tablets were compact and hard. The thickness of the tablets ranged from 4.00 to $7.50\left(\mathrm{Kg} / \mathrm{cm}^{2}\right)$. All the formulations satisfied the content of the drug and good uniformity in drug content was observed. Thus all the physical attributes of the prepared 
tablets were establish be practically within control. The tablets were evaluated for in vitro dissolution studies in phosphate buffer $\mathrm{pH} 7.4$ for $30 \mathrm{~min}$. The results of the optimized formulation F-6 showed maximum drug release i.e. $94.78 \%$ at the end of $30 \mathrm{~min}$. The results of release studies of formulations F-6 was shown in Table 6

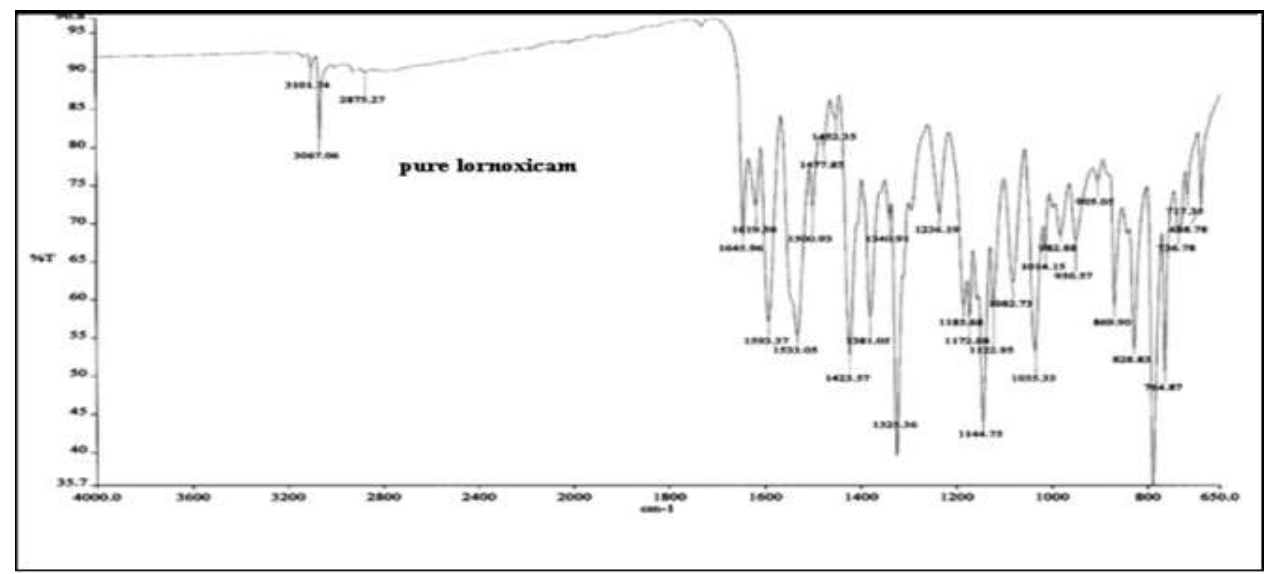

Figure 1 FT-IR Spectra of pure LXM

Table 4 Result of pre-compression properties of different formulations of the LXM

\begin{tabular}{|c|c|c|c|c|c|}
\hline \multirow[b]{2}{*}{ Batches } & \multicolumn{5}{|c|}{ Precompression Parameters } \\
\hline & $\mathrm{BD}\left(\mathrm{gm} / \mathrm{cm}^{3}\right)$ & TD $\left(\mathrm{gm} / \mathrm{cm}^{3}\right)$ & Angle of repose $(\theta)$ & Carr's index (\%) & Hauser's ratio \\
\hline F1 & 0.530 & 0.613 & $27.45 \pm 0.01$ & 14.16 & 1.15 \\
\hline F2 & 0.529 & 0.589 & $28.60 \pm 0.03$ & 10.78 & 1.11 \\
\hline F3 & 0.553 & 0.623 & $30.01 \pm 0.01$ & 11.86 & 1.12 \\
\hline F4 & 0.601 & 0.677 & $25.10 \pm 0.04$ & 11.91 & 1.12 \\
\hline F5 & 0.555 & 0.625 & $23.71 \pm 0.01$ & 11.83 & 1.12 \\
\hline F6 & 0.370 & 0.410 & $20.17 \pm 0.01$ & 10.17 & 1.10 \\
\hline
\end{tabular}

Table 5 Results of post compression properties of LXM tablets

\begin{tabular}{|c|c|c|c|c|c|c|}
\hline \multirow[b]{2}{*}{ Tests } & \multicolumn{6}{|c|}{ Batch } \\
\hline & F1 & F2 & F3 & F4 & F5 & F6 \\
\hline Average Diameter $(8.0 \pm 0.2 \mathrm{~mm})$ & 7.94 & 7.99 & 8.00 & 8.20 & 8.10 & 8.01 \\
\hline Average Thickness $(4.4 \pm 0.2 \mathrm{~mm})$ & 4.47 & 4.29 & 4.45 & 4.50 & 4.49 & 4.42 \\
\hline Average Weight (250.0 mg $\pm 7.5 \%)$ & 250.40 & 250.18 & 250.53 & 251.62 & 249.86 & 250.07 \\
\hline$\% \mathrm{Wt}$. Variation ( $\pm 7.5 \%$ of Avg.Wt) & \pm 4.2 & \pm 4.8 & \pm 3.6 & \pm 3.9 & \pm 3.9 & \pm 2.0 \\
\hline Hardness $\left(\mathrm{Kg} / \mathrm{cm}^{2}\right)$ & 4.00 & 4.50 & 4.20 & 5.20 & 4.90 & 7.50 \\
\hline Friability (NMT $1 \% \mathrm{w} / \mathrm{w}$ ) & 0.45 & 0.48 & 0.51 & 0.38 & 0.45 & 0.42 \\
\hline Disintegration time(NMT 3 min) & $1 \mathrm{~min}$ & $50 \mathrm{Sec}$ & $1.3 \mathrm{~min}$ & $58 \mathrm{sec}$ & $1.1 \mathrm{~min}$ & $30 \mathrm{sec}$ \\
\hline Taste Observed & $\begin{array}{l}\text { Bitter after } \\
\text { taste }\end{array}$ & $\begin{array}{l}\text { Bitter after } \\
\text { taste }\end{array}$ & $\begin{array}{c}\text { Bitter after } \\
\text { taste }\end{array}$ & $\begin{array}{c}\text { Bitter after } \\
\text { taste }\end{array}$ & $\begin{array}{c}\text { Slight taste } \\
\text { masking }\end{array}$ & $\begin{array}{c}\text { Taste } \\
\text { masked }\end{array}$ \\
\hline
\end{tabular}

Table 6 In-vitro drug release data of formulation F-6

\begin{tabular}{|c|c|}
\hline Time (min) & Cumulative*\% Drug Release \\
\hline 5 & 45.50 \\
\hline 10 & 58.00 \\
\hline 15 & 66.15 \\
\hline 20 & 81.16 \\
\hline 30 & 94.78 \\
\hline
\end{tabular}

\section{CONCLUSION}

Thus from the whole research work it can be concluded that the oral disintegrating tablet of LXM were formulated and evaluated for a variety of parameters. From the compatibility studies by IR of drug it was establish to be compatible with other formulation excipients. All evaluation parameter were within specification. The croscarmellose sodium shown faster drug release than crospovidone. Formulation F-6 release maximum drug within the 30 mins.ie. $94.78 \%$ and 
shown minimum disintegration time i.e. $30 \mathrm{sec}$ than other formulation and hence measured best formulation.

\section{REFERENCES}

1. Bala R, Pawar P, Khanna S, Arora S. Quick dissolving films-a novel approach to drug delivery. Int J Pharm Invest 2003; 3(2):31-34. https://doi.org/10.4103/2230-973X.114897

2. Sabatini N. Recent patents concerning organoleptic and healthy properties of table olives. Recent Pat Chem Eng 2009; 2(1):3742. https://doi.org/10.2174/2211334710902010037

3. Sheth SK, Patel SJ, Shukla JB. Formulation and evaluation of taste masked oral disintegrating tablet of lornoxicam. Int J Pharma Bio Sci 2010; 1(2): 1-9.

4. Gupta H, Sharma A, Kumar S, Roy SK. E-Tongue: a tool for taste evaluation. Recent Pat Drug Deliv Formul 2010; 4(1):82-89. https://doi.org/10.2174/187221110789957309

5. Mundada AS, Jain S, Chachda NO, Avari JG. Taste masking approaches-a review: part I. American Pharm Rev 2008; 11(3):94-102.

6. Gosai AR, Patil SB, Sawant KK. Formulation and evaluation of orodispersible tablets of ondansetron hydrochloride by direct compression using superdisintegrants. Int J Pharm Sci Nanotechnol. 2008; 26(1):106-111. https://doi.org/10.37285/10.37285/ijpsn.2008.1.1.10

7. Pandey P, Dahiya M. Oral disintegrating tablets: a review. Int J Pharma Res \& Rev 2016; 5(1):50-62.

8. Konapure SA, Chaudhari PS, Oswal RJ, et al. Mouth dissolving tablets an innovative technology. Int J Appl Biol Pharml Tech 2011; 2(1):496-503.

9. Sreekanth J, Janardhan D, Kumar P T P, Krishna M V. Formulation and evaluation of baclofen orally disintegrating tablets. Int J Pharm Sci Nanotech 2010; 2(4):733-38. https://doi.org/10.37285/ijpsn.2009.2.4.7
10. Bakde VB, Hedau AS. Design, development and evaluation of orodispersible drug delivery system of taste masked famotidine by newer range of ion-exchange resin. 3495/MUM/2012.

11. Hamza YE-S, Aburahma MH. Design and in vitro evaluation of novel sustained-release double-layer tablets of lornoxicam: utility of cyclodextrin and xanthan gum combination. AAPS Pharm Sci Tech. 2009; 10(4):1357. https://doi.org/10.1208/s12249-009-9336-9

12. Sakore S, Chakraborty B. Formulation and evaluation of enalapril maleate sustained release matrix tablets. Int J Pharm Biomed Res 2013; 4:21-6.

13. Udayakumar T, Suresh AG, Ubaidulla U. Formulation and evaluation of immediate and sustained release bilayered tablet with glibenclamide and metformin Hcl. Int J Res Dev Pharm Sci 2013; 2:337-43.

14. Shashidhar P, Vidya Sagar G, Srikanth G. Design and in-vitro evaluation of metformin hydrochloride (SR) and glimepiride (IR) as bilayered tablets. Int J Pharm Chem Sci 2013; 2:780-92.

15. Sridhar Babu G, Vijay Kumar D, Aishwarya M, Malathy PS, Redya Naik R. Formulation and in vitro characterization of sustained release matrix tablets of metformin Hcl. J Glob Trends Pharm Sci 2014; 5:2085-92.

16. Saluja V, Garg C. Once-daily sustained-release matrix tablets of metformin hydrochloride based on an enteric polymer and chitosan. J Pharm Educ Res 2013; 4:92-7.

17. Salsa T, Veiga F, Pina ME. Oral controlled-release dosage forms. i. cellulose ether polymers in hydrophilic matrices Drug Dev Ind Pharm. 1997; 23:929-938. https://doi.org/10.3109/03639049709148697

18. Liberman HA, Leon L, Schwartz JB. The Theory and Practise of Industrial Pharmacy, Varghese Publishing House, Mumbai, 3rd edition, 1987, 296-303. 